\title{
A OBJEÇÃO DA JUSTIÇA NO UTILITARISMO DE J. S. MILL
}

\author{
The objection of justice on J. S. Mill's utilitarianism
}

Bruno Botelho Braga*

\begin{abstract}
Resumo: Meu objetivo neste trabalho é apresentar uma reconstrução da argumentação de Mill acerca da possível relação entre justiça e utilidade, isto é, a resposta do filósofo britânico às clássicas objeções de que o utilitarismo seria um preceptor de injustiças. Neste sentido, procurarei mostrar como a justiça pode ser corretamente justificada dentro da perspectiva da utilidade. Pretendo realizar tal objetivo em três momentos. Em primeiro lugar, exponho de maneira breve os fundamentos do utilitarismo na perspectiva de Mill. Em seguida, apresento os subprincípios do utilitarismo para localizar o foco das críticas. Por fim, discuto os dois momentos da argumentação de Mill no intuito de responder a tais críticas.
\end{abstract}

Palavras-chave: Utilitarismo. Agregacionismo. Justiça.
Abstract: My aim on this paper will be to present a reconstruction of Mill's arguments regarding the possible relationship between justice and utility, that is, Mill's answer to the classical objections that utilitarianism would be a preceptor of injustices. In this sense, I will try to show how justice can be correctly justified within utility's perspective. I intend to do so in three steps: Firstly, with a brief explanation about the foundations of utilitarianism on Mill's perspective. After, I present the subprinciples of utilitarianism in order to locate the main focus of critics. Finally, I discuss the two moments of Mill's argumentation in order to answer these critics.

Keywords: Utilitarianism. Agregationism. Justice.

*Mestrando em Filosofia na Universidade Federal de Pelotas - Bolsista CAPES. Contato: brunobotelhobraga@yahoo.com.br

\begin{tabular}{|c|c|c|c|c|c|}
\hline Intuitio & $\begin{array}{c}\text { ISSN } \\
1983-4012\end{array}$ & Porto Alegre & Vol.9- No.2 & $\begin{array}{c}\text { Dezembro } \\
2016\end{array}$ & pp. 74-87 \\
\hline
\end{tabular}




\section{Introdução}

Que o utilitarismo enquanto teoria minimalista ${ }^{1}$ seja de extrema relevância para a resolução de dilemas em ética prática, não há qualquer dúvida². No entanto, no que concerne ao âmbito do justo, a convicção é radicalmente oposta. Tal fragilidade não é discussão recente. Já Mill se preocupou em rebater diversas críticas e ferrenhas objeções àquilo que seria o ponto mais fraco do princípio da utilidade, qual seja, sua contra-intuitividade no âmbito da justiça. O capítulo V de Utilitarianism - última parte a ser lançada pelo autor na Fraser's Magazine ${ }^{3}$ - é o maior da obra, e não sem motivos. Nele, Mill ensaia uma tentativa de aproximar justiça e utilidade, procurando reduzir a primeira à segunda.

Meu objetivo, portanto, será o de apresentar uma reconstrução da argumentação millseana acerca da possível relação entre justiça e utilidade, isto é, a resposta de Mill às clássicas objeções de que o utilitarismo seria um preceptor de injustiças, além de procurar salientar como o justo pode ser justificadamente compreendido dentro da perspectiva da utilidade. Farei isso começando por uma breve exposição dos fundamentos do utilitarismo na perspectiva de Mill. Em seguida, apresento os subprincípios do utilitarismo para localizar o foco das críticas. Por fim, discuto os dois momentos da argumentação de Mill para responder a tais críticas.

Vejamos, de antemão, a formulação canônica do princípio da utilidade proposta por Mill em Utilitarianism II. $2^{4}$ :

O credo que aceita a utilidade, ou o Princípio da Maior Felicidade, como fundamento da moralidade, defende que as acções estão certas na medida em que tendem a promover a felicidade, erradas na medida que tendem a produzir o reverso da felicidade. Por

\footnotetext{
1 Quando falo em minimalismo, tenho em mente a simplicidade do princípio da utilidade no que tange à sua aplicabilidade. Tal simplicidade pode parecer tácita quando o utilizamos para solucionar dilemas éticos. No entanto, não devemos nos iludir. No âmbito de sua fundamentação normativa ou em formulações de teorias do valor, o caso é bem outro. Além disso, o utilitarismo é famoso pela sua capacidade de, ao mesmo tempo, ser intuitivo e contraintuitivo. O que quero dizer? Parece de total acordo que devemos, como agentes éticos, promover a felicidade do mundo. Por outro lado, e sem entrar em detalhes acerca de qual tipo de utilitarismo estamos a tratar, a gama de contraexemplos e aparentes absurdidades geradas pelo princípio é algo a se levar em consideração. Portanto, devemos ser cautelosos ao chamar o utilitarismo de "teoria minimalista".

${ }^{2}$ As aplicações do utilitarismo de preferências a casos controversos como o aborto e a eutanásia, por exemplo. Neste sentido, conferir: Singer, P. Practical Ethics, Cambridge University Press, Cambridge, 1980; second edition, 1993; third edition, 2011.

${ }^{3}$ O Utilitarismo foi publicado pela primeira vez no volume 64 do periódico inglês Fraser's Magazine (1861). As partes 1 e 2 em outubro, as partes 3 e 4 em novembro, e a parte 5 - que trata da justiça - em dezembro.

4 Todas as citações serão feitas conforme a convenção dos textos de Mill: capítulo/parágrafo. Nesse caso: II. 2. Não citarei o nome da obra, já que todas as citações serão oriundas do Utilitarianism, aqui, seguindo a tradução portuguesa seguinte: Mill, J.S. Utilitarismo. Trad: Pedro Galvão. Porto, Portugal: Porto Editora, 2005.
}

\begin{tabular}{|c|c|c|c|c|c|}
\hline Intuitio & $\begin{array}{c}\text { ISSN } \\
1983-4012\end{array}$ & Porto Alegre & Vol.9- No.2 & $\begin{array}{c}\text { Dezembro } \\
2016\end{array}$ & pp. 74-87 \\
\hline
\end{tabular}


felicidade, entende-se o prazer e a ausência de dor; por infelicidade, a dor e a privação de prazer.

Não devemos nos iludir com a aparente simplicidade do princípio. Com uma leitura mais atenta é possível, e mesmo necessário, fazer a seguinte consideração: o princípio da utilidade é um arranjo de elementos relacionados entre si que podem ser desmembrados para uma análise individual e independente. Mas não faremos isso por enquanto.

Além do que foi dito, devemos ter em mente outros dois elementos indispensáveis para a compreensão do conteúdo normativo próprio do hedonismo de Mill, quais sejam, o conceito de qualidade e o procedimento dos “juízes competentes”. Diferente de Bentham, que considerava o valor dos prazeres apenas sob uma ótica quantitativa ${ }^{5}$, Mill, no intuito de defender seu antecessor das acusações de ser entusiasta de uma doutrina para porcos ${ }^{6}$ - pois não distinguia prazeres animais de outros propriamente humanos - introduz a distinção qualitativa dos prazeres, isto é, a regra segundo a qual deve haver uma descontinuidade intrínseca entre tipos de prazer, regra essa que seja capaz de promover uma relação dicotômica "superior/inferior"7:

É totalmente compatível com o princípio da utilidade reconhecer o facto de que alguns tipos de prazer são mais desejáveis e valiosos que outros. Seria absurdo supor que, enquanto que na avaliação de todas as outras coisas se considera tanto a qualidade como a quantidade, a avaliação dos prazeres dependesse apenas da quantidade ${ }^{8}$.

E segue:

Se me perguntarem o que entendo pela diferença qualitativa de prazeres, ou por aquilo que torna um prazer mais valioso do que outro, simplesmente enquanto prazer e não por ser maior em quantidade, só há uma resposta possível. De dois prazeres, se houver um ao qual todos ou quase todos aqueles que tiveram a experiência de ambos derem uma preferência decidida, independentemente de sentirem qualquer obrigação moral para o preferir, então será esse o prazer mais desejável ${ }^{9}$.

Donner, neste sentido, sintetiza perfeitamente o hedonismo sui generis de Mill:

O hedonismo qualitativo de Mill consiste em uma caracterização da utilidade como um complexo estado mental que leva em consideração a qualidade, bem como a quantidade das experiências aprazíveis na mensuração do seu valor, e permanece como uma sofisticada alternativa ao hedonismo quantitativo de Bentham ${ }^{10}$.

5 São sete as medidas de quantidade que Bentham apresenta: intensidade, duração, certeza, proximidade, fecundidade, pureza e extensão. No entanto, as medidas de intensidade e duração são as mais relevantes para 0 caráter normativo do prazer.

${ }^{6}$ II. 3

${ }^{7}$ II. 4

${ }^{8}$ II. 4

${ }^{9}$ II. 5

${ }^{10}$ DONNER, W. Mill’s Utilitarianism. In: Skorupski, J. (ed.) Cambridge Companion to Mill. Cambridge, 1997, p. 257, tradução nossa.

\begin{tabular}{|c|c|l|l|c|c|}
\hline Intuitio & $\begin{array}{c}\text { ISSN } \\
1983-4012\end{array}$ & Porto Alegre & Vol.9- $\mathrm{N}^{\mathrm{o} .2}$ & $\begin{array}{c}\text { Dezembro } \\
2016\end{array}$ & pp. 74-87 \\
\hline
\end{tabular}


Visto que, então, as ações corretas são aquelas que maximizam um saldo líquido positivo de experiências aprazíveis ao maior número de envolvidos, e que tais experiências devem ser medidas não apenas por sua intensidade e duração ${ }^{11}$, mas também por sua qualidade, que tipo de regra deve-se adotar para que saibamos objetivamente distinguir quais são os prazeres superiores e quais são os inferiores, haja visto a multiplicidade subjetiva de concepções acerca do que é prazeroso?

Mill nos introduz aos juízes competentes para responder tal questionamento:

Se um dos dois for colocado, por aqueles que estão competentemente familiarizados com ambos, tão acima do outro que eles o preferem mesmo sabendo que é acompanhado de um maior descontentamento, e se não abdicariam dele por qualquer quantidade do outro prazer acessível à sua natureza, então teremos razão para atribuir ao deleite preferido uma superioridade em qualidade que ultrapassa de tal modo a quantidade que esta se torna, por comparação, pouco importante ${ }^{12}$.

Aqueles que experenciaram ambos os tipos de prazer e que, por sua experiência, são capazes de oferecer um veredicto último e confiável acerca da relação qualitativa entre prazeres diferentes, são então aptos a fazer parte desse conjunto que, para Mill, constitui o critério evidencialista ${ }^{13}$ possível e suficiente para tal definição gradativa. Mill é um empirista e, por isso, aceita como critério último e irrevogável o tribunal dos juízes competentes como definidor justificado deste tipo de relação ${ }^{14}$.

\footnotetext{
${ }^{11}$ Quando fala em "quantidade", Mill, no entanto, parece ter em mente apenas a intensidade, ou, ao menos, parece dar um maior peso a essa propriedade quantitativa, como lemos no seguinte trecho: "Por isso, esses sentimentos e esse juízo têm à mesma consideração quando declaram que, independentemente da questão da intensidade, o tipo de prazeres resultantes das faculdades superiores é preferível ao daqueles que são acessíveis à natureza animal separada das faculdades superiores.” (II.8, grifo meu exceto em "tipo").

12 (II. 5) Muito se discutiu se Mill, ao introduzir o conceito de qualidade, estaria abandonando o hedonismo. Em II.2 o autor afirma que o bem-estar consiste em experiências aprazíveis, e que tais experiências são boas unicamente pela sua própria aprazibilidade. Nesse sentido, "mais prazeroso" seria equivalente a "mais valioso". No entanto, ao afirmar que podemos, e mesmo devemos, preferir certas experiências como qualitativamente superiores, embora elas possam ser acompanhadas de um maior descontentamento, Mill estaria afirmando que é possível algo ser "mais valioso" mesmo sendo "menos prazeroso". O conceito de qualidade, segundo a crítica, seria uma propriedade nãohedônica que possibilitaria às experiências serem mais valiosas mesmo sem serem prazerosas. Se este é o caso, então Mill estaria advogando uma espécie de hedonismo misto, ao incluir outra propriedade, que não somente o prazer, como determinante para a constituiçao do valor das experiências. Para aprofundar o tema, ver: West, H.R. Mill's Qualitative Hedonism. Philosophy 51, 1976. No entanto, a bibliografia sobre o tema é bastante vasta.

${ }^{13}$ De acordo com Crisp (1997, p. 36), os juízes competentes ou a sua maioria, oferecem uma razão evidencial, suficiente e última para a determinação de quais prazeres são superiores e quais são inferiores. Isso não significa afirmar que eles sejam definidores do valor dos prazeres, isto é, não significa dizer que algo tem valor por causa da preferência dos juízes, antes que é o fato de algo ter valor que determina a preferência dos juízes. $\mathrm{O}$ argumento de Crisp para essa leitura é o seguinte: Mill afirma que os J.C. julgam também a intensidade dos prazeres. Visto que não haveria sentido em dizer, no contexto quantitativo, que a intensidade é determinada pela preferência dos J.C., mas antes que eles julgam porque a intensidade é X ou Y, e visto que, segundo Crisp, os J.C. julgam do mesmo modo quantidade e qualidade, então não há sentido em afirmar que é a preferência dos J.C. que determina o valor dos prazeres, mas antes que é o valor e a natureza destes que servem de razão para a preferência dos J.C.

${ }^{14}$ II. 5
}

\begin{tabular}{|c|c|l|l|c|c|}
\hline Intuitio & $\begin{array}{c}\text { ISSN } \\
1983-4012\end{array}$ & Porto Alegre & Vol.9- N $^{\circ} .2$ & $\begin{array}{c}\text { Dezembro } \\
2016\end{array}$ & pp. 74-87 \\
\hline
\end{tabular}


Que tipo de objeções enfrenta, então, o utilitarismo, no que tange à justiça? Uma das mais clássicas críticas é descrita por Mulgan ${ }^{15}$ revisitando o apontamento de Rawls: é dito que "a falha principal do utilitarismo, porquanto se concentra na utilidade agregada, ignora ou subestima o aspecto da independência entre as pessoas ${ }^{16}$.” Mas o que isso significa? Retomemos então o princípio da utilidade e o vejamos mais de perto. Que subprincípios ele comporta?

De acordo com Carvalho ${ }^{17}$ temos os seguintes elementos:

(i) Consequencialismo: A qualidade moral das ações se dá em função de suas consequências. Ações corretas ou certas são as que produzem consequências boas; ações incorretas ou erradas as que produzem consequências más.

(ii) Hedonismo: Por conseqüências boas se entende a felicidade ou o prazer; por conseqüências más, a infelicidade ou a dor.

(iii) Agregacionismo: Ao avaliar ações, temos que somar as unidades de felicidade e de infelicidade e extrair a diferença. A correção de um curso de ação é determinada pelo saldo líquido de felicidade, isto é, a felicidade que resta, descontado o sofrimento engendrado.

(iv) Maximacionismo: O utilitarismo apregoa que devemos optar por aquele curso de ação que produz o maior saldo líquido de felicidade, levando-se em conta todos os seres dotados de sensibilidade, afetáveis por nossas ações ${ }^{18}$.

O que nos interessa aqui é (iii), o agregacionismo, pois é onde as críticas focam sua atenção. Em suma, tal sub-princípio nos diz que devemos sempre levar em consideração não apenas um ou outro indivíduo, mas sim todos aqueles que podem sofrer algum tipo de influência da nossa ação, ou seja, que devemos priorizar o balanço positivo entre prazer e dor tendo em vista sempre o ganho geral em termos sociais. Em outras palavras, o bem-estar geral é maior que o bem-estar individual, e um ganho balanceado no primeiro justifica certas perdas no segundo. Isto se dá porque o agregacionismo é construído a partir da seguinte conclusão feita por Mill no Capítulo IV, onde trata da prova do utilitarismo: “(...) que a felicidade

\footnotetext{
${ }^{15}$ MULGAN, T. Utilitarismo. Trad: Fábio Creder. 2a ed. Petrópolis, RJ: Vozes, 2014, p. 11.

${ }^{16}$ Um trecho mais extenso acerca da posição de Rawls (1971, p. 26-27): “A característica marcante da visão utilitarista da justiça consiste em que não importa, senão indiretamente, como essa soma de satisfações é distribuída entre os indivíduos, assim como não importa, senão indiretamente, como um homem distribui suas satisfações ao longo do tempo. A distribuição correta em ambos os casos é aquela que produz a máxima realização (...) $\mathrm{O}$ utilitarismo não leva a sério a distinção entre as pessoas”.

${ }^{17}$ CARVALHO, M.C.M. John Stuart Mill: O Utilitarismo Reiventado. In: O Utilitarismo em Foco: um encontro com seus proponentes. CARVALHO, Maria Cecília Maringoni de (Org.). Florianópolis: Ed.UFSC, p. 75.

${ }^{18}$ Carvalho, no entanto, não crê que Mill seja um maximacionista, pois, segundo a autora "ele (Mill) não apregoa o dever de maximizar o bem, mas apenas assevera, como citado acima, que 'as ações são certas na medida em que tendem a produzir a felicidade e erradas na medida em que tendem a produzir o contrário da felicidade’”.
}

\begin{tabular}{|c|c|c|c|c|c|}
\hline Intuitio & $\begin{array}{c}\text { ISSN } \\
1983-4012\end{array}$ & Porto Alegre & Vol.9 $-\mathrm{N}^{\circ} .2$ & $\begin{array}{c}\text { Dezembro } \\
2016\end{array}$ & pp. 74-87 \\
\hline
\end{tabular}


de cada pessoa é um bem para essa pessoa e, logo, a felicidade geral um bem para o agregado de todas as pessoas"19.

Não pretendo, aqui, questionar diretamente os fundamentos do utilitarismo, pois isso demandaria um espaço muito maior e específico para $\operatorname{tal}^{20}$. O que me interessa neste momento é, dadas as críticas, mostrar que Mill não se preocupou em defender propriamente seu sistema no nível fundamental, isto é, em abandonar ou reestruturar a tese agregacionista, mas sim em formular uma noção de justiça que pudesse ser compatível com o princípio da utilidade. Mill irá propor que o justo é nada mais do que uma manifestação da utilidade social em um meio específico, a saber, o âmbito dos direitos individuais ${ }^{21}$. Embora as críticas procurem salientar a contra-intuitividade deste aspecto agregacionista - aspecto que está por detrás dos contra-exemplos à concepção de justiça do utilitarismo, Mill não aceitava críticas desta estirpe, como veremos a seguir.

Por enquanto, vejamos o seguinte exemplo:

Você é o xerife de uma cidade isolada do oeste selvagem. Um assassinato foi cometido. A maioria das pessoas aceita que Bob é culpado, mas você sabe que ele é inocente. A menos que você enforque Bob agora, haverá uma revolta na cidade e várias pessoas morrerão. O utilitarismo diz que você deve enforcar Bob, porque a perda da sua vida é superada pelo valor de se prevenir o motim ${ }^{22}$.

19 IV. 3

${ }^{20}$ Sobre a prova do utilitarismo de Mill, ver: WEST, H. R. Mill's 'proof' of the principle of utility. In: H.B. Miller and W.H. Williams (eds). The Limits of Utilitarianism, Minneapolis, 1982.

${ }^{21} \mathrm{O}$ principal objetivo de Mill no capítulo V de Utilitarianism é mostrar que o âmbito do justo, em última instância, se reduz a um âmbito estritamente moral e, por conta disso, as regras de justiça podem ser avaliadas e testadas através do princípio da utilidade. Seu foco é apontar que, se as noções de justiça e utilidade forem devidamente compreendidas, é possível compatibilizá-las. Neste sentido, o âmbito próprio dos deveres de justiça é nada mais que um âmbito moral (não algo sui generis), que se distingue apenas por dizer respeito à considerações de direito individual. Portanto, tal como as demais regras morais, os deveres de justiça também são passíveis de serem testados pelo padrão utilitarista.

${ }^{22}$ MULGAN, T. Utilitarismo. Trad: Fábio Creder. $2^{\text {a }}$ ed. Petrópolis, RJ: Vozes, 2014, p. 133. O exemplo do xerife é apenas um dentre os diversos exemplos considerados por Mulgan. Além de exemplos que procuram retratar a aparente (digo aparente porque diversas formas de utilitarismo, inclusive a de Mill, livra-se com relativa facilidade de exemplos deste tipo) injustiça do princípio, temos diversos outros que procuram nos chamar a atenção para as altas e por vezes absurdas exigências que o utilitarismo produziria. Vejamos outro exemplo, semelhante ao do xerife, que pode ser, a critério de maior ilustração, apresentado. As mesmas resoluções de Mill ao primeiro aplicam-se ao segundo: suponha que você é um médico cirurgião em um hospital no centro da cidade. Você tem quatro pacientes precisando urgentemente de transplante. Um precisa de coração, outro de fígado, um terceiro precisa de estômago e o último necessita de pulmões. Você recebe um novo paciente que está apenas com uma forte gripe. O utilitarismo exige que você mate o paciente saudável, pegue seus órgãos e transplante-os para os pacientes necessitados, já que, ao fazer isso, você está promovendo mais bem-estar ao mundo do que se escolhesse não fazê-lo. Devemos, no entanto, ser cautelosos ao considerar tal exemplo. Um utilitarista não considera apenas as consequências imediatas da ação, mas também as consequências de longo prazo. Sendo assim, matar uma pessoa inocente, sem questionamentos, para salvar a vida de outras, não parece ser um curso de ação que, a longo prazo, traria mais felicidade que infelicidade, pois a insegurança gerada nos seres humanos por conta disso seria catastrófica. Em verdade, esse é um ponto positivo do utilitarismo de regras, conquanto ele leva-nos a perguntar “e se isso se tornasse uma regra?” ou “e se isso fosse feito por todos?” A partir disso rejeitaríamos tal ato porque ele, enquanto regra, não promoveria o bem-

\begin{tabular}{|c|c|c|c|c|c|}
\hline Intuitio & $\begin{array}{c}\text { ISSN } \\
1983-4012\end{array}$ & Porto Alegre & Vol.9- No.2 & $\begin{array}{c}\text { Dezembro } \\
2016\end{array}$ & pp. 74-87 \\
\hline
\end{tabular}


Este contraexemplo mostra claramente que a querela se foca no aspecto agregacionista do princípio. A contraintuitividade, ou o "incômodo provocado", se encontra exatamente no fato de ser permitida uma supressão dos direitos individuais em prol de uma maximização do bem-estar geral. No entanto, esta aparente "injustiça” não recebe tal titulação aos olhos de Mill. Em verdade, a situação como um todo é justificadamente justa, desde que compreendamos como o âmbito do justo se conecta às bases do princípio da utilidade. É o que Mill pretende justificar ao longo do Capítulo V de Utilitarianism, isto é, revisitar o conceito de justiça para compatibilizá-lo com certos elementos inerentes ao príncipio. Com isso, Mill crê ser possível responder a tais objeções, não reformulando os fundamentos agregacionistas de sua teoria, mas sim procurando relacionar justiça e utilidade, ou seja, mostrando como a primeira procede justificadamente da segunda.

\section{III}

Vimos em linhas gerais a estrutura conceitual básica do utilitarismo, bem como em qual elemento as críticas se focam. Vejamos agora, então, como Mill procura responder a tais objeções e desqualificar os contraexemplos comumente apresentados. Ressalto apenas que, embore Mill não apresente as objeções no corpo do texto, é clara a sua preocupação com o dito aspecto “contraintuitivo” que o utilitarismo promove no âmbito da justiça.

Sua tentativa de responder a tais objeções tem um caráter duplo:

(i) Background metaético: Mill nega que a intuição de um agente seja reveladora de uma realidade objetiva no que tange à princípios morais. Portanto, desqualificará os contraexemplos como sendo de fato contraexemplos, pois alegar contraintuitividade, para Mill, não tem peso justificatório. O que é dito ser um exemplo de injustiça intuitiva, para Mill, será apenas um caso claro de justiça aos moldes utilitaristas, e estes, por sua vez, são justificados, já que o princípio da utilidade é devidamente provado ${ }^{23}$. Sobre este

estar geral. Para aprofundar a temática regra/ato, ver: Richard Brandt. Ethical Theory. Prentice Hall, 1959. Brandt foi o pioneiro do uso das expressões "utilitarismo de ato e de regra".

${ }^{23}$ Mulgan (MULGAN, T. Utilitarismo. Trad: Fábio Creder. 2a ed. Petrópolis, RJ: Vozes, 2014, p. 142) nos apresenta uma interessante distinção. Segundo o autor, a mais simples resposta (dentre outras possíveis) às objeções e contraexemplos levantados contra o utilitarismo centra-se em "rejeitar o uso de intuições particulares para testar uma teoria moral. Por mais contra-intuitiva ou exigente que seja a moralidade, não podemos rejeitar as suas exigências simplesmente porque as consideramos intragáveis.” Normalmente, utilitaristas desta estirpe rejeitam todos os distanciamentos do seu ponto de partida utilitarista. Singer, acerca deste ponto, corretamente afirma: "A maneira como as pessoas de fato efetivamente julgam nada tem a ver com a validade da minha conclusão.” (Singer, Peter. Famine, Affluence and Morality. Philosophy and Public Affairs. Princeton University Press. 1971, p. 236). Este parece ser o teor da resposta de Mill às objeções de contra-intuitividade, como vemos na passagem de V.2 citada no corpo de texto.

\begin{tabular}{|c|c|c|c|c|c|}
\hline Intuitio & $\begin{array}{c}\text { ISSN } \\
1983-4012\end{array}$ & Porto Alegre & Vol.9- No.2 & $\begin{array}{c}\text { Dezembro } \\
2016\end{array}$ & pp. 74-87 \\
\hline
\end{tabular}


aspecto, não me deterei mais, pois meu foco é no compatibilismo entre justiça e utilidade ${ }^{24}$. Entretando, vejamos o que o autor diz a respeito deste assunto:

(...) embora uma coisa seja acreditar que temos sentimentos naturais de justiça e outra seja reconhecê-los como critério último de conduta, estas duas opiniões estão, de facto, estreitamente ligadas. Os seres humanos estão sempre predispostos a acreditar que qualquer sentimento subjectivo que não consigamos explicar de outra maneira, é uma revelação de alguma realidade objectiva ${ }^{25}$.

(ii) Redução da justiça à utilidade social: Todo o Capítulo V de Utilitarianism é uma tentativa de mostrar como podemos derivar o conceito de justiça a partir do princípio da utilidade. Nesta seção, portanto, pretendo mostrar como Mill transforma contra-exemplos do tipo apresentado na seção anterior (i), em exemplos simples de casos onde vemos a justiça utilitarista operando. Em suma, o próximo passo visa demonstrar que onde antes se via "injustiça”, agora, vê-se "justiça”26.

Sua argumentação tem quatro passos centrais: primeiro, Mill promove uma investigação do termo “injustiça” através de uma análise objetiva dos casos onde tal nome é proferido. Segundo, uma análise etimológica do termo “justiça”. Terceiro, apela para as noções de “dever de obrigação perfeita e imperfeita” para isolar o âmbito próprio da justiça. E, por último, ele propõe compatibilizarmos os resultados obtidos com certos elementos da natureza humana que são próprios do princípio da utilidade.

Os casos que Mill aponta como sendo nichos de aplicação do termo "injustiça” são os seguintes:

(a) Injustiça legal: Privar alguém de sua liberdade pessoal, de sua propriedade ou de qualquer outra coisa que lhe pertença por lei. Em suma, privar os direitos legais de um indivíduo ${ }^{27}$.

\footnotetext{
${ }^{24}$ Mill fala em "sentimentos subjetivos”, e não explicitamente em "intuições”. A meu ver, entretanto, Mill utiliza-os como sinônimos, fazendo clara referência ao moral sense defendido pelos intuicionistas. Digo ainda que se alguma dúvida resta sobre o pano de fundo da crítica de Mill, podemos observar logo no primeiro capítulo de Utilitarianism sua explícita querela com o intuicionismo: "Não se consegue evitar a dificuldade recorrendo à teoria popular segundo a qual há uma faculdade racional, um sentido ou instinto, que nos informa acerca daquilo que está certo e errado. Afinal, além de a própria existência de um tal sentido moral ser uma das questões em disputa, mesmo aqueles que acreditam nessa faculdade e têm algumas pretensões filosóficas foram obrigados a abandonar a ideia de que, tal como os nossos outros outros sentidos discernem as imagens ou sons efectivamente presentes, também ela discerne aquilo que está certo e errado no caso particular que enfrentamos.” (I.3)

${ }^{25}$ (V. 2) De acordo com Crisp (CRISP, R. Routledge Philosophy Guidebook to Mill on Utilitarianism. London/New York: Routledge Philosophy Guidebooks, 1997, p. 157, tradução nossa): "Mill não nega a existência ou mesmo a respeitabilidade do 'sentimento' ou do ultraje moral que sentimos (...) Ele afirma, entretanto, que apesar da sua intensidade, não somos forçados a ver nosso sentimento de justiça como uma 'revelação de alguma realidade objetiva'. Pode ser natural o suficiente, mas essencialmente 'animal' em oposição a uma resposta 'intelectual', uma origem que pode consistentemente ser explicada através do utilitarismo. Isto é, pode ser um simples sentimento ou emoção, e não uma resposta a algum princípio genuíno em conflito com o utilitarismo”.

${ }^{26}$ Embora concorde que (i) o utilitarismo de Mill é muito menos exigente do que os contra-exemplos supõem e (ii) que o status normativo dos direitos, para o pensador britânico, tem prioridade sobre as exigências morais (o que por si só já resolveria os aparentes problemas), neste trabalho procuro destacar a descaracterização que Mill parece fazer do apelo à intuitividade como fonte de objeção à doutrina utilitarista. Mill parece crer que as intuições é que devem se conformar à teoria, não o contrário.
}

${ }^{27}$ V. 5.

\begin{tabular}{|c|c|l|l|c|c|}
\hline Intuitio & $\begin{array}{c}\text { ISSN } \\
1983-4012\end{array}$ & Porto Alegre & Vol.9- N $^{\circ} .2$ & $\begin{array}{c}\text { Dezembro } \\
2016\end{array}$ & pp. 74-87 \\
\hline
\end{tabular}


(b) Injustiça moral: Quando há a violação de um direito moral. Acertadamente, Mill reconhece que existem casos onde uma lei pode ser injusta e, por isso, há o problema da legitimidade em violar esta lei. Ao mesmo tempo em que parece ser injusto violar uma lei, parece justo violá-la caso ela seja uma lei injusta. Mill conclui, então, que embora o sentimento de injustiça oriundo de uma violação legal seja semelhante ao sentimento proporcionado em nós por uma lei injusta - já que também viola os direitos individuais - por serem casos de algum modo diferentes, devem ser devidamente classificados. Uma infração da lei é injusta, pois priva ou viola os direitos de alguém, mas uma lei injusta em si mesma possui um caráter diferente, porque apesar de violar um direito, não transgride um direito garantido pela própria lei, como é o caso da injustiça legal. Portanto, sua transgressão é moral, isto é, uma lei injusta viola um direito moral, não legal ${ }^{28}$.

(c) Reciprocidade: É injusto que uma pessoa obtenha um bem ou sofra um mal que não merece. Em suma, parece ser uma indicação de justiça quando alguém que fez o bem mereça o bem, e aquele que fez o mal, receba em troca, o mal ${ }^{29}$.

(d) Promessas: É um sinal de injustiça faltar à palavra. Para Mill, nesse caso, injustiça é não somente quebrar promessas, mas também violar compromissos ou até mesmo frustrar expectativas suscitadas pelo próprio caráter moral ${ }^{30}$.

(e) Imparcialidade: É injusto mostrar predileção ou preferência por uma pessoa em detrimento de outra em questões nas quais a predileção ou preferência não sejam apropriadas. Neste trecho há uma discussão mais aprofundada. Mill considera que, em verdade, a imparcialidade não é, de fato, um quinto elemento per se, mas sim uma espécie de instrumento necessário para os demais. Ele conclui isso, pois parece concordar com o fato de que, na grande maioria dos casos, a parcialidade não é censurável. Não afirmamos ser injustiça o fato de alguém dar predileção a amigos ou familiares em casos domésticos ou similares. A imparcialidade, quando exigida, demanda que se tenha em consideração apenas as partes tomadas em igualdade, como detentores de direitos individuais de mesmo peso. A imparcialidade não é uma exigência absoluta, mas sim relativa a casos onde tal propriedade seja exigida ${ }^{31}$.

A partir disso, Mill afirma:

Resumindo, pode-se dizer que, enquanto obrigação de justiça, a imparcialidade significa ser influenciado exclusivamente pelas considerações que é suposto deverem influenciar o caso particular em questão, bem como resistir à solicitação de quaisquer motivos que induzam uma conduta diferente daquela que essas considerações ditariam ${ }^{32}$.

\footnotetext{
${ }^{28}$ V. 6.

${ }^{29}$ V. 7.

${ }^{30}$ V. 8.

${ }^{31}$ V. 9.

${ }^{32}$ V. 9.
}

\begin{tabular}{|c|c|l|l|c|c|}
\hline Intuitio & $\begin{array}{c}\text { ISSN } \\
1983-4012\end{array}$ & Porto Alegre & Vol.9- No.2 & $\begin{array}{c}\text { Dezembro } \\
2016\end{array}$ & pp. 74-87 \\
\hline
\end{tabular}


(f) Igualdade: Definitivamente o tópico mais controvérso. Mill afirma que é reconhecido por todos o fato de que a igualdade parece ser o fundamento mais valioso da justiça. Entretanto, afirma que as concepções acerca do que tal conceito significa são várias e incomensuráveis. Alguns afirmam que os que trabalham mais ou prestam um trabalho mais valioso devem receber mais, e que isso é a verdadeira igualdade; outros afirmam que os mais necessitados devem receber mais. Neste emaranhado de diferentes concepções igualmente justificáveis, Mill afirma ser impossível, neste momento, oferecer uma conclusão unificadora ${ }^{33}$.

Para o autor é impossível encontrar, dentre as diferentes aplicações do termo “justiça”, um elo que sirva para formular um conceito unívoco e suficientemente abrangente do que ela de fato é34. Qual é o significado etimológico, então, da palavra “justiça” em sua origem histórica? É a partir dessa resposta que Mill pretende delimitar o escopo parcial do que contém a ideia de justiça e, por conseguinte, direcionar justificadamente, em favor do utilitarismo, o sentimento que sanciona tal regra:

Na maior parte das línguas, ou mesmo em todas elas, a etimologia da palavra que corresponde a "justo" aponta para uma origem ligada à lei positiva ou àquilo que, na maior parte dos casos, foi a forma primitiva da lei - o costume autoritário Justum é uma forma de jussum, aquilo que foi ordenado. Jus tem a mesma origem. Díkaion vem de diké, cujo significado principal, pelo menos nas épocas históricas da Grécia, era petição jurídica. Inicialmente, na verdade, significava apenas o modo ou maneira de fazer as coisas, mas depressa acabou por significar a maneira prescrita de fazer as coisas, aquilo que as autoridades reconhecidas (patriarcais, judiciais ou políticas) obrigariam a fazer. Recht, de onde veio right e righteous, é sinônimo de lei. Na verdade, o significado inicial de recht não apontava para lei, mas para rectidão física, do mesmo modo que wrong e os seus equivalentes latinos significavam torcido ou tortuoso. (...) Os tribunais de justiça e a administração da justiça são os tribunais e a administração da lei. $L a$ justice, em francês, é o termo estabelecido para a administração judicial ${ }^{35}$.

A partir desta averiguação etimológica, Mill conclui que aquilo que está presente nas palavras de quase todos os povos é a ideia de conformidade à leis ${ }^{36}$. Os termos “justiça” e "lei” estão extremamente conectados desde os primórdios dos seus usos. Entretanto, embora tal concepção ocorra desse modo especialmente entre os hebreus e cristãos - já que admitem a legitimidade da lei como um fato primordial baseado na boa vontade divina, isso não é o caso entre os povos gregos. Nestes, era devidamente sabido que as leis são formuladas por homens, e que por isso podem ser injustas e parcialmente convenientes. Sendo assim, a formulação inicial da ideia de justiça, para Mill, é a conformidade às leis que deveriam existir, isto é, aquelas leis que não ferem certos preceitos morais anteriores ${ }^{37}$.

\footnotetext{
${ }^{33}$ V. 10.

${ }^{34}$ V. 11.

${ }^{35}$ V. 12.

${ }^{36} \mathrm{~V} .12$.

${ }^{37}$ V. 12.
}

\begin{tabular}{|c|c|c|c|c|c|}
\hline Intuitio & $\begin{array}{c}\text { ISSN } \\
1983-4012\end{array}$ & Porto Alegre & Vol.9- $\mathrm{N}^{\circ} .2$ & $\begin{array}{c}\text { Dezembro } \\
2016\end{array}$ & pp. 74-87 \\
\hline
\end{tabular}


Juntamente com esta ideia encontra-se a de punição ou “cumprimento do dever”. Na medida em que o justo está representado objetivamente como uma conformidade à leis moralmente justas, como se comporta o sentimento interno de justiça e o que ele demanda? Quando contemplamos a violação de uma lei - que deveria existir - temos um sentimento interno de retaliação, ou seja, desejamos fortemente que aquele que violou tal lei seja punido veementemente, pois a demanda do sentimento implica um forte dever em conformidade com as exigências da justiça.

Mas, ainda não há como diferenciar esta ideia de outros sentimentos morais ${ }^{38}$. Até aqui, não se percebe o que há de específico na ideia de justiça e no sentimento correspondente que possa diferenciá-lo de qualquer outro sentimento. Coragem, temperança ou justiça, implicam a ideia de uma conformidade à leis e de um desejo de retaliação àquele que comete uma transgressão. Obviamente, e quero deixar claro, não estou afirmando coragem ou temperança como previstas e mesmo obrigadas por lei, contudo, é relevante aqui é a ideia de punição que subjaz a conformidade ou não à leis, sejam tais punições penais, como ocorre no caso da justiça, ou sejam certos constrangimentos morais, como é o caso da coragem e da temperança. A partir apenas disso, porém, não há como distinguir claramente tal sentimento correspondente de outros sentimentos morais, pois, internamente, todos os sentimentos estão submetidos às mesmas forças, a saber, o desejo de retaliação e o de descumprimento de um dever.

Mill apela então para a distinção entre deveres de obrigação perfeita e imperfeita para especificar o tipo de sentimento que é próprio da justiça:

\begin{abstract}
Ora, sabe-se que os autores de ética dividem os deveres morais em duas classes denotadas por expressões infelizes: os deveres de obrigação perfeita e os deveres de obrigação imperfeita. Os últimos são aqueles em que, embora o acto seja obrigatório, as ocasiões específicas para o realizar ficam a nosso critério. [...] Na linguagem mais precisa dos juristas filosóficos, os deveres de obrigação perfeita são aqueles deveres em virtude dos quais um direito correlativo reside em alguma pessoa ou pessoas: os deveres de obrigação imperfeita são aquelas obrigações que não dão origem a qualquer direito ${ }^{39}$.
\end{abstract}

Os deveres de obrigação imperfeita não especificam quaisquer ocasiões específicas para os realizarmos. São casos como a benevolência ou a generosidade, isto é, embora tenhamos uma obrigação moral em fazê-los, eles não geram direitos para os indivíduos. Os deveres de obrigação perfeita, por outro lado, estipulam ações específicas que devem ser feitas em ocasiões específicas. Geram um direito correlativo e permitem aos indivíduos exigir o cumprimento de tais direitos.

Com isso, Mill define que as duas características primordiais do sentimento de injustiça são: (i) o desejo de castigar alguém que causa danos e (ii) que esses danos violem certos direitos individuais ${ }^{40}$. $\mathrm{O}$

\footnotetext{
${ }^{38}$ V. 14.

${ }^{39}$ V. 15.

${ }^{40}$ V. 18.
}

\begin{tabular}{|c|c|c|c|c|c|}
\hline Intuitio & $\begin{array}{c}\text { ISSN } \\
1983-4012\end{array}$ & Porto Alegre & Vol.9- $\mathrm{N}^{\circ} .2$ & $\begin{array}{c}\text { Dezembro } \\
2016\end{array}$ & pp. 74-87 \\
\hline
\end{tabular}


primeiro provém do significado etimológico da palavra e o segundo da especificidade dos deveres de obrigação perfeita.

Ora, mas agora podemos nos questionar: de que modo estes elementos podem ser relacionados ao princípio da utilidade? O que há nestas características que permite Mill afirmar que o âmbito da justiça deve estar submetido aos ditâmes do utilitarismo?

Segundo o filósofo britânico, o primeiro destes elementos, a saber, o desejo de retaliação, pode ser reduzido à duas características essenciais da natureza humana, quais sejam, o instinto de autodefesa e o sentimento de simpatia ${ }^{41}$. O primeiro confere vivacidade ao desejo de retaliação, enquanto que o segundo justifica a moralização do desejo sob o limiar da utilidade social. O impulso de auto-defesa produz o desejo de retaliação a todos aqueles que praticam algum tipo de injustiça. Somado ao sentimento de simpatia, ele é alargado a todos que violam os direitos individuais. A utilidade social se torna, então, o critério último da noção de justiça, e é justificada por um apelo à certos elementos da natureza humana compatíveis com o princípio da utilidade. Essas características naturais tornam o indivíduo preocupado com o bem-estar geral, isto é, os mesmos elementos que legitimam o modelo de racionalidade prática consequencialista legitimam, também, quando somados à esfera dos direitos individuais, o âmbito da justiça $^{42}$.

Mill encerra o Utilitarianism com a seguinte constatação:

A justiça permanece o nome apropriado para certas utilidades sociais que, enquanto classe, são muitíssimo mais importantes e, por isso, mais absolutas e imperiosas do que qualquer outras (embora possam não o ser em casos particulares). Por essa razão, devem ser, e são-no naturalmente, vigiadas por um sentimento diferente não só em grau, mas também em género, distinto do sentimento mais brando que está ligado à simples ideia de promover o prazer ou conveniências humanas em virtude da natureza mais definida dos seus mandamentos e da maior severidade das suas sanções ${ }^{43}$.

De acordo com o visto até aqui, Crisp corretamente conclui:

Para sumarizar, então, Mill acredita ter refutado o problema da justiça do seguinte modo. Primeiro, podemos entender a causa de termos um sentimento tão forte uma vez que reconheçamos a sua origem natural como um dispositivo para a proteção de importantes interesses. Segundo, já que tais interesses são tão importantes, o utilitarismo por si

\footnotetext{
${ }^{41}$ (V.19) Em poucos momentos da obra vemos Mill apresentar explicitamente sua concepção de natureza humana. No entanto, creio que ela esteja subsumida na formulação do princípio da utilidade. Ao contrário de Bentham, Mill se preocupou em oferecer uma "prova” para o princípio que advoga. Em vez de simplesmente apresentar uma concepção de natureza humana e, a partir disso, extrair conclusões normativas, Mill se preocupou em formular o princípio da utilidade primeiro, para, a partir disso, buscar justificação empírica para a desejabilidade de tal princípio. Provando, através de argumentos, a desejabilidade do princípio da utilidade, prova-se, ao mesmo tempo e indiretamente, a natureza humana que subjaz tal aceitabilidade tácita.
}

42 V. 20.

${ }^{43}$ V. 38.

\begin{tabular}{|c|c|c|c|c|c|}
\hline Intuitio & $\begin{array}{c}\text { ISSN } \\
1983-4012\end{array}$ & Porto Alegre & Vol.9- $\mathrm{N}^{\circ} .2$ & $\begin{array}{c}\text { Dezembro } \\
2016\end{array}$ & pp. 74-87 \\
\hline
\end{tabular}


mesmo recomenda que continuemos falando em justiça e injustiça, mesmo embora tal conversa seja meramente um instrumento para a maximização do bem-estar geral ${ }^{44}$.

Por fim, gostaria apenas de retomar de modo geral os principais pontos abordados neste trabalho com o intuito de clarificar a unidade argumentativa do mesmo.

\section{Conclusão}

Primeiramente, fiz uma exposição geral sobre o utilitarismo de Mill, esclarecendo sua funcionalidade e seus principais elementos, como o conceito de qualidade e o de juízes competentes. Isto serviu para nos dar uma visão geral de como tal teoria normativa opera. Num segundo momento, apresentei os subelementos do princípio da utilidade no intuito de mostrar que as críticas, em geral, se focam no agregacionismo. Nesse sentido, procurei apresentar um contraexemplo clássico para exemplificar o teor geral das críticas. No terceiro e mais importante momento, mostrei como Mill procura desqualificar tais críticas e o contra-exemplo apresentado por mim. Sua argumentação tem dois momentos centrais. Em primeiro lugar, oferece uma crítica à intuição como reveladora da realidade objetiva do justo e, assim, desconsidera o caráter contraintuitivo como sendo, de fato, um argumento. Em segundo lugar, procura compatibilizar as ideias de justiça e utilidade. Mill faz isso a partir de uma redução das duas características essenciais do conceito de justiça, a saber, o desejo de retaliação e a violação dos direitos individuais, aos mesmos elementos da natureza humana que são responsáveis pela preocupação com a utilidade social.

A partir disso conclui-se que, embora as características essenciais do utilitarismo possam ser criticadas, ainda sim o sistema normativo, como um todo, é extremamente coerente e capaz até mesmo de abrigar sob seu paradigma a ideia de justiça. Embora os contraexemplos procurem promover uma inquietação intuitiva acerca das consequências aparentemente incomuns do princípio, Mill consegue demonstrar que a justiça pode ser devidamente compreendida como uma manifestação da utilidade social no âmbito dos direitos individuais.

\section{Referências}

BENTHAM, J. 1789: An Introduction to the Principles of Morals and Legislation. London: mod. edn ed. H.L.A.Hart and F.Rosen, Oxford, 1995.

CRISP, R. Routledge Philosophy Guidebook to Mill on Utilitarianism. London/New York: Routledge Philosophy Guidebooks, 1997.

${ }^{44}$ CRISP, R. Routledge Philosophy Guidebook to Mill on Utilitarianism. London/New York: Routledge Philosophy Guidebooks, 1997, p. 162.

\begin{tabular}{|c|c|l|l|c|c|}
\hline Intuitio & $\begin{array}{c}\text { ISSN } \\
1983-4012\end{array}$ & Porto Alegre & Vol.9- No.2 & $\begin{array}{c}\text { Dezembro } \\
2016\end{array}$ & pp. 74-87 \\
\hline
\end{tabular}


CARVALHO, M.C.M. John Stuart Mill: O Utilitarismo Reiventado. In: O Utilitarismo em Foco: um encontro com seus proponentes. Maria Cecília Maringoni de Carvalho (org.). - Florianópolis: Ed. Da UFSC. Pp. 73-104.

DONNER, W. Mill's Utilitarianism. In: Skorupski, J. (ed.) Cambridge Companion to Mill. Cambridge, 1997

MILL, J.S. Utilitarismo. Trad: Pedro Galvão. Porto, Portugal: Porto Editora, 2005.

MILL, J.S. Utilitarianism. Ed. T.N.R. Rogers. New York: Dover Publications, 2007.

MULGAN, T. Utilitarismo. Trad: Fábio Creder. 2. Ed. Petrópolis, RJ: Vozes, 2014.

SINGER, Peter. Famine, Affluence and Morality. Philosophy and Public Affairs. Princeton University Press. 1971. P. 229-243.

RAWLS, John (1971). A Theory of Justice (Original ed.). Cambridge, Mass.: Belknap Press of Harvard University Press.

Recebido em: 16 de outubro de 2016.

Aprovado para a publicação em 10 de novembro de 2016. 